\title{
Professoras e crianças pequenas no contexto da Educação Infantil pelotense em meados do século $X X$
}

\section{Teachers, kindergarten and preschool children in the context of childhood education in Pelotas in the mid 20th century}

\author{
Lourdes Helena Dummer Venzke ${ }^{1}$ \\ Jane Felipe ${ }^{2}$
}

\begin{abstract}
RESUMO
Este artigo aborda uma pesquisa realizada nas primeiras instituições escolares de Pelotas/RS que se dedicaram ao atendimento de crianças pequenas, sem o caráter asilar, em meados do século XX. Tais espaços apresentam as marcas deixadas pelos desafios assumidos em nome da proteção e educação dessas crianças. Essa pesquisa, de cunho qualitativo, teve como aporte teórico os estudos de gênero, os estudos culturais e autores/as pós-estruturalistas. Os materiais coletados e os contextos nos quais eles foram produzidos indicaram alguns elementos que compunham o cenário no qual as professoras desenvolveram seu trabalho. Com esta pesquisa tornou-se possível visibilizar como as professoras foram representadas e como o exercício da docência na Educação Infantil estava atrelado à resolução de alguns problemas sociais. Nesse sentido, as exigências atribuídas às docentes incorporam os valores pertinentes a um dado período histórico, com seus diferentes momentos e necessidades apontadas.
\end{abstract}

Palavras-chave: professoras; crianças pequenas; Educação Infantil.

DOI: $10.1590 / 0104-4060.38714$

1 Instituto Federal de Educação, Ciência e Tecnologia Sul-rio-grandense Campus Pelotas - Visconde da Graça. Pelotas, Rio Grande do Sul, Brasil. Setor de Ensino. Avenida Eng. Ildefonso Simões Lopes, 2791. CEP: 96060-290.

2 Universidade Federal do Rio Grande do Sul. Faculdade de Educação. Porto Alegre, Rio Grande do Sul, Brasil. Avenida Paulo Gama, s/nº Prédio 12201. CEP: 90046-900. 


\begin{abstract}
The present article approaches a research carried out at the first school institutions in Pelotas/RS which focused on helping kindergarten and preschool children, without an asylum character, in the mid $20^{\text {th }}$ century. Such spaces present the marks left by the challenges assumed in the name of the protection and education of these children. This research, a qualitative one, had as technical support some studies on gender, cultural studies and post-structuralist authors. The collected materials and the contexts in which they were produced indicated some elements which comprised the scenario in which the teachers developed their work. With this research it was possible to highlight how the teachers were represented and how the teaching practice in Childhood Education was connected to the resolution of some social problems. Therefore, the demands attributed to the teachers incorporate relevant figures to a certain historical period, with their different moments and necessities pointed out.
\end{abstract}

Keywords: teachers; preschool children; Childhood Education.

Este artigo $^{3}$ aborda uma pesquisa realizada nas primeiras instituições escolares de Pelotas/RS que se dedicaram ao atendimento de crianças pequenas, sem o caráter asilar, para buscar informações sobre o contexto em que atuavam as professoras de Educação Infantil, especialmente nas décadas de 1940 a 1960 - período em que houve progressivo investimento nessa área da educação na referida cidade. Esta pesquisa, de cunho qualitativo, teve como aporte teórico os estudos de gênero, os estudos culturais e autores/as pós-estruturalistas. Foram investigados documentos escolares escritos - pastas sobre a história das escolas, atas de reuniões pedagógicas, regimentos escolares, álbuns, etc. - contendo várias informações sobre o atendimento infantil. Em virtude da escassez desses documentos, foi necessário recorrer aos dois jornais locais mais importantes "Diário Popular" e "A Opinião Pública" - a fim de conseguir subsídios para

3 Fruto de uma parte da pesquisa realizada durante o Doutorado em Educação. (VENZKE, 2010).

4 Jornal fundado em 27 de agosto de 1890. Segundo informações do site <www.diariopopular.com.br>, esse jornal é o terceiro mais antigo do Brasil e o mais antigo do Rio Grande do Sul. Desde sua fundação até 1930 foi considerado o porta-voz do Partido Republicano Rio-grandense (LONER, 1998), no entanto, precisou se adequar às transformações políticas, sociais e econômicas que foram se delineando no decorrer das décadas até os dias atuais.

5 Sua publicação diária iniciou em 05 de maio de 1896 e também se identificava com as ideias republicanas, sofrendo algumas mudanças de acordo com a posição da direção e da redação do jornal. (LONER, 1998). O jornal circulou até 1962, com algumas interrupções. 
este estudo. Os excertos utilizados neste texto respeitam a grafia usual da época, os possíveis erros ortográficos ou de impressão neles contidos são colocados entre aspas e em itálico para diferenciá-los das citações bibliográficas.

As instituições pelotenses pioneiras no que se refere à atenção especial à primeira infância e que ainda mantêm este atendimento no século XXI foram instaladas em contextos diferenciados durante o século passado. Tais espaços apresentam as marcas deixadas pelos desafios assumidos em nome da proteção e educação das crianças menores de seis anos de idade. Como aconteceu em outros lugares do Brasil ${ }^{6}$, havia em Pelotas/RS um tratamento diferenciado para as crianças pequenas conforme a sua classe social.

As crianças das classes menos favorecidas eram atendidas em creches assistenciais ou públicas, cuja preocupação maior era com o seu cuidado - alimentação, higiene e segurança - e não com o seu desenvolvimento intelectual, enquanto que aquelas pertencentes às classes média e alta dispunham de um atendimento considerado mais moderno nos chamados Jardins de Infância ${ }^{7}$, que visavam ao desenvolvimento psicomotor, cognitivo e afetivo, preparando-as para o então Ensino Primário.

Assim, as creches priorizavam os cuidados básicos e os Jardins de Infância a educação das crianças. No entanto, segundo Kuhlmann Jr. (2001), as creches também educavam, porém para a submissão das crianças de classes populares e de suas famílias, evidenciado por meio do atendimento de baixa qualidade destinado a essa camada da população, visando à prevenção da criminalidade ao retirar essas crianças das ruas. Além disso, nas creches o trabalho era desenvolvido principalmente por mulheres que não possuíam formação específica; no Jardim de Infância, por sua vez, as professoras, segundo alguns registros, eram formadas no Curso Normal. Cabe esclarecer que, na década de 1960, começava a ser exigido um curso de especialização para as "jardineiras" que,

6 Segundo Tisuko Morchida Kishimoto (1986), Moysés Kuhlmann Júnior (2001) e Zilma Ramos de Oliveira (1995), o atendimento infantil tem sido desenvolvido no Brasil com base em duas concepções de serviços: a chamada "assistencial" para as crianças pobres em instituições como as creches, salas de asilo e escolas maternais, e a do tipo "educacional", para as crianças das classes média e alta, nos Jardins de Infância e nas pré-escolas.

7 O Jardim de Infância foi criado por Friedrich Fröebel no século XIX, na Alemanha, partindo do princípio de que a criança é como uma planta em formação que necessita de cuidados periódicos para crescer de maneira saudável. Para tanto, é indispensável o trabalho da/o jardineira/o, encarregada/o de proporcionar as condições para o crescimento e desenvolvimento da criança, atendendo as suas necessidades. Essa proposta pedagógica espalhou-se por vários países, no entanto, passou por algumas adaptações nos diferentes contextos em que foi implantada. As suas ideias também ganharam força no Brasil, culminando com o surgimento de turmas de jardim ainda nas últimas décadas daquele século. Para mais informações, ver Arce (2002a, 2002b) e Pinazza (2005). 
em Pelotas, foi promovido pelo Instituto Estadual de Educação Assis Brasil, conforme documentos arquivados nessa instituição sobre tal curso ${ }^{8}$.

As primeiras instituições pelotenses, das redes privada e pública, voltadas, exclusivamente ou não, para a primeira infância são as seguintes: Colégio São José (1910), Instituto Estadual de Educação Assis Brasil (1929), Casa da Criança São Francisco de Paula (1936), Escola Municipal de Ensino Fundamental Luciana de Araújo (1950) e Escola Municipal de Arte e Infância Ruth Blank (1963). A própria localização desses espaços educativos direcionava, em parte, o público-alvo. Essas instituições, localizadas no centro da cidade ou nas proximidades, beneficiavam as crianças que moravam perto ou que podiam se deslocar com mais facilidade.

Na visão de Felipe (2000), os Jardins de Infância foram importantes no processo de formação da criança pequena, pois se constituíram como espaços de observação, experimentação e produção de saberes referentes à infância, com vistas ao governo (no sentido foucaultiano) das crianças. A autora enfatiza, também, a indissociabilidade entre os discursos voltados para as crianças e as mulheres, sendo a educação feminina - preparo para as funções domésticas e maternas - produzida por discursos sob a ótica masculina, em que as mulheres deveriam educar a prole servindo de sustentáculo moral e afetivo do lar.

O termo governo, na perspectiva foucaultiana, possui uma conotação distinta da que é usada apenas para designar ações de caráter político e gestor do Estado e demais estruturas políticas. Refere-se à "maneira de dirigir a conduta dos indivíduos ou dos grupos" (FOUCAULT, 1985, p. 240), tanto externa quanto internamente (governo de si).

Nessa perspectiva, o Jardim de Infância teve uma contribuição significativa ao promover o controle da conduta infantil, principalmente através da formação de hábitos e atitudes, imprescindíveis numa sociedade que se pretendia moderna e próspera. As professoras "jardineiras" tiveram uma função importante no desenvolvimento desse projeto, por serem as profissionais encarregadas de executá-lo junto às crianças pequenas. Em Pelotas, não há registros de professores homens que tenham trabalhado em Jardins de Infância, no período delimitado (décadas 1940-1960) para esta investigação. Para justificar este fato, são encontrados argumentos tais como: quanto menor a criança, mais cuidados necessita de um adulto e que, na maioria das culturas, são destinados às mulheres; a feminização do magistério; as mulheres possuem determinadas representações - amorosa,

8 Intitulado "Formação de Professôres Especializados em Educação Pré-Primária", conforme Projeto referente ao "Planejamento para 1962" e livro de matrículas do referido curso, que passou a funcionar a partir do $1^{\circ}$ semestre de 1963. 
atenciosa, paciente, etc. - consideradas importantes para o trabalho com crianças pequenas; dentre outros.

Dessa forma, há toda uma produção cultural discursiva sobre a mulher e o homem, indicando os espaços considerados "mais adequados" para ocuparem na nossa sociedade. Assim, a Educação Infantil foi construída como um espaço predominantemente feminino, pois as mulheres são consideradas as cuidadoras e educadoras "naturais" das crianças, e, consequentemente, desvalorizado socialmente, como todo espaço que possui essa predominância, pois a ideia de que o sustento da família cabe ao homem e de que a mulher trabalha para os "seus alfinetes" ainda estava muito arraigada.

Esses fatores favoreceram a formação de muitas professoras para o Ensino Fundamental e também para a Educação Infantil. No caso do Jardim de Infância, mais ainda, pois a atuação neste espaço exigia curso de pós-formação/ especialização ${ }^{9}$. Essa exigência consta no trecho de uma reportagem publicada no final da década de 1960, em um jornal local. "Para ensinar no pré, além de fazer o curso normal, a professôra é obrigada a ter um ano de especialização nos Institutos de Educação do Estado ou em escolas particulares." (DIÁRIO Popular, 07/07/1968, p. 7, $1^{\circ}$ caderno).

Cabe lembrar que nem sempre as exigências legais foram cumpridas de fato, pois as condições de formação e de trabalho não tiveram a garantia para isso, especialmente do poder público. Além disso, a jardineira (professora) e as plantas (crianças) estavam vinculadas a representações ${ }^{10}$ que descreviam o trabalho docente e o discente de maneira oposta e complementar. Oposta porque indicava tarefas distintas e delimitadas para as protagonistas. À jardineira cabia desempenhar o "papel" de autoridade exemplar e de orientadora das atividades infantis, a fim de que as plantas crescessem e desabrochassem, conforme a proposta de Friedrich Fröebel (século XIX). Já às plantas, por sua vez, ficava o desafio da obediência e do cumprimento das tarefas, com êxito. Essa analogia expressa que, assim como as jardineiras cuidavam de suas plantas com dedicação e afinco, as professoras do Jardim de Infância deveriam ter esse sentimento e cuidado com as crianças pequenas sob sua responsabilidade.

9 Conforme previa o Parecer $n^{\circ} 111$, de 02 de abril de 1965, do Centro de Pesquisas e Orientações Educacionais, pertencente à então Secretaria de Estado dos Negócios de Educação e Cultura/RS.

10 A representação não funciona como um reflexo da realidade, mas sim como sua constituidora, podendo produzir efeitos sobre os sujeitos. A partir desse ponto de vista, a representação é "entendida como inscrição, marca, traço, significante; considerada a face visível do conhecimento". (SILVA, 1999, p. 32). E, ainda, as representações "são múltiplas, mas elas podem, também, se transformar ou se contrapor [...] elas estão estreitamente vinculadas ao poder". (LOURO, 1999, p. 102). 
A partir dessas considerações, referimos as instituições pelotenses que contribuíram com a educação e o cuidado de inúmeras crianças pequenas, ao longo de várias décadas do século XX e que continuam em funcionamento no presente século.

\section{Instituições pioneiras na educação da primeira infância em Pelotas/RS}

Em Pelotas/RS, merecem destaque as instituições que foram pioneiras no atendimento da primeira infância, tanto da rede de ensino privada quanto da pública. Essas instituições desenvolveram suas atividades administrativas e pedagógicas, seguindo o ideário dos contextos local e nacional, no que diz respeito à educação das crianças pequenas.

A Casa da Criança São Francisco de Paula - designação recebida em 1957 e que mantém até hoje, porém, atendendo às determinações da Lei de Diretrizes e Bases da Educação Nacional (LDB, Lei no 9.394/1996) passou a ser Escola de Educação Infantil - foi construída em 1936, através de iniciativa da sociedade civil e da Igreja Católica, sendo a primeira creche de Pelotas. Essa instituição foi implantada em uma época de conturbados acontecimentos políticos, como a instalação do Estado Novo ${ }^{11}$.

Em nome da filantropia, que é a marca registrada dessa instituição desde o início das suas atividades, anunciava-se inclusive em jornais, que tinha a "missão de preparar para a vida futuros brasileiros que, sem sua assistência estariam destinados a perecer ou a serem enxovalhados no enorme caudal dos vícios que corrompem a humanidade". E ainda, "não pode haver obra mais útil do que transformar esses pequeninos seres em homens úteis a sua pátria." (A OPINIÃO Pública, 09/06/1943, p. 4). Para tanto, contava com o trabalho e a dedicação das Irmãs Missionárias de Jesus Crucificado junto às crianças de seis meses a sete anos incompletos. Tem-se a presença das religiosas, principalmente católicas, como uma característica acentuada na cidade de Pelotas no que se refere à educação institucionalizada, no início do século XX. Isso se deve prin-

11 Período que vai de 1937 a 1945, no qual Vargas deu um golpe de estado implantando um governo autoritário e centralizador; promulgou a Constituição de 1937, suprimindo a liberdade partidária, a independência entre os poderes executivo, legislativo e judiciário, bem como o federalismo existente. Criou o Departamento de Imprensa e Propaganda (DIP) para controlar e censurar manifestações contrárias ao seu governo, além de difundir a ideologia do Estado Novo. Vargas perseguiu seus opositores, principalmente os políticos partidários do comunismo. 
cipalmente ao fato do poder público somente assumir a instrução de crianças a partir dos sete anos de idade, o que era considerado de sua responsabilidade. Essa situação nessa cidade iria mudar, aos poucos, através de algumas iniciativas envolvendo o governo estadual, na década de 1940, e o governo municipal, na década de 1950, conforme será apresentado posteriormente.

Cabe mencionar que as creches eram consideradas um "mal necessário" (VIEIRA, 1986; KUHLMANN JR., 2001), pois no imaginário social daquela época o melhor lugar para a criança de até seis anos era o seu lar, sob os cuidados de sua mãe. A maternidade, por sua vez, seria o "destino natural" da mulher, a "fonte de realização e felicidade plena", atendendo as expectativas da sociedade. (FELIPE, 2000, p. 176). Assim, a maternidade era tida como incompatível com o trabalho externo, pois, na medida do possível, a mulher deveria cuidar da casa e dos/as filhos/as enquanto o homem buscaria o sustento da família. Entretanto, os problemas familiares advindos da precária situação financeira aumentaram a necessidade da mulher trabalhar fora da esfera doméstica, bem como a importância que passou a ser dada à realização profissional feminina. Dessa forma, as creches serviriam apenas para amenizar esses problemas, além de combater as chamadas criadeiras - mulheres que tomavam conta das crianças, em suas casas, enquanto suas mães trabalhavam -, que eram rechaçadas pelos sanitaristas por serem pessoas sem a formação adequada. No entanto, as mulheres que trabalhavam nas creches também não tinham uma formação específica e eram aceitas porque estavam sob um controle médico-higienista sistemático, restringindo-se, dessa forma, a qualidade do atendimento das crianças pequenas aos aspectos da saúde e da segurança.

Nesse sentido, a Casa da Criança São Francisco de Paula possui, em seus arquivos, relatórios que detalham as atividades administrativas e financeiras dessa instituição e nos quais explicitam os seus "fins principais":

[...] 'receber, guardar e instruir, durante o dia, crianças de ambos os sexos, até a idade máxima de cinco anos, cujos pais por suas condições de vida e de trabalho, não lhes possam prestar esses cuidados. A Créche dispensa gratuitamente a essas crianças, abrigo, alimentação, vestimenta, higiêne, assistência médica, educação doméstica, religiosa, moral e cívica.' (RELATÓRIO da Presidente: Ano social de 1939 a 1940, 26/05/1940).

Quanto à educação da primeira infância, na década de 1950 do século $\mathrm{XX}$, as creches e parques infantis que atendiam crianças em período integral passaram a ser procuradas também por trabalhadoras do comércio e funcionárias 
públicas, além das operárias e empregadas domésticas. (OLIVEIRA, 2002). Tal fato se deveu ao aumento da participação da mulher no mercado de trabalho ocasionado pelo avanço da industrialização e da urbanização no país, o que de certa forma favoreceu a expansão e ampliação desses espaços infantis.

Organizações intergovernamentais, principalmente a Organização das Nações Unidas para a Educação, a Ciência e a Cultura' ${ }^{12}$ (UNESCO), o Fundo das Nações Unidas para a Infância ${ }^{13}$ (UNICEF) e a Organização Mundial para a Educação Pré-Escolar ${ }^{14}$ (OMEP), a partir da década de 1950, influenciaram na nova proposta brasileira para o atendimento pré-escolar, que visava ao trabalho de assistência às crianças pobres. Começava, então, a surgir no Brasil o modelo de uma pré-escola de massa. É possível afirmar que nesse contexto foram estabelecidas relações de poder na busca de uma definição dos rumos a seguir quanto ao cuidado e amparo das crianças em situação de vulnerabilidade social. Ou seja, os sujeitos e as instituições imbuídas de maior autoridade ditaram as normas e definiram as ações consideradas mais adequadas para aquele contexto em que se expandia a educação pré-escolar.

Nesse período, o prédio da Casa da Criança São Francisco de Paula foi ampliado tendo em vista a qualidade do Jardim de Infância ${ }^{15}$. Esse empreendimento somente se efetivou depois de um estudo minucioso das condições do prédio e das impressões relatadas pela "Madre" em visita a vários estabelecimentos de Porto Alegre/ $\mathrm{RS}^{16}$. No entanto, a sua inauguração aconteceu somente em julho de 1956, após várias campanhas junto à comunidade pelotense para angariar fundos, possibilitando também a aquisição de mobiliário específico para as crianças dessas turmas.

A preocupação com a educação das crianças menos favorecidas está registrada em textos que referem o trabalho da Casa da Criança São Francisco

12 Criada em 16/11/1945, logo após a Segunda Guerra Mundial. Áreas de atuação da UNESCO: Educação, Ciências Naturais, Humanas e Sociais, Cultura, Comunicação e Informação.

13 Criado em 11/12/1946, como fundo de emergência para ajudar as crianças que sofreram com a guerra. Em 1953, tornou-se instituição permanente de ajuda e proteção a crianças de todo o mundo.

14 Órgão consultivo da UNESCO e do UNICEF, fundada em 1948 para assistir crianças vítimas da Segunda Guerra Mundial. Ampliou-se para vários países. O Comitê Nacional Brasileiro da OMEP foi fundado em 1953, no Rio de Janeiro. Trata-se de uma entidade de âmbito nacional, filantrópica, suprapartidária, sem discriminações raciais, filosóficas ou religiosas. Constitui-se por federações que atuam em vários estados e que são formadas pelas associações regionais ou municipais.

15 O funcionamento da primeira turma dessa instituição começou em 13 de agosto de 1944, a partir da designação de uma professora pela Secretaria da Educação, conforme Portaria ${ }^{\circ} 4.229$, de 14/07/1944. (LIVRO de Atas no 1, Ata n ${ }^{\circ} 71,25 / 08 / 1944$ ).

16 Essa visita possibilitou "ampliar conhecimentos e colher novas idéias para o Jardim da Infância" e constatar que a "Creche está em ótimas condições, podendo com a nova ala, ficar à altura dos mesmos". (Ata n 137, 30/05/1952). 
de Paula, como o transcrito abaixo, reforçando a afirmação de Kuhlmann Jr. (2001) que as creches educavam as classes populares objetivando a prevenção da criminalidade dentro da sociedade. Além disso, as entidades mantidas pela iniciativa privada são justificadas pela ausência de políticas públicas que atendessem às necessidades da população de baixa renda.

Créche São Francisco de Paula

Crianças que desde os primeiros momentos da sua existência sofrem as conseqüências da falta de alimentação, de higiene e mais tarde de educação, transformam-se em indivíduos perniciosos ao organismo social, quando a sua índole, a natureza de seus sentimentos poderiam ser aproveitados para a formação de homens de bem, concientes de seu papel no seio da sociedade.

Está provado que a formação de um povo não pode ser estruturada de outra forma si não pela mais eficiente assistência desde a base, isto é, desde a infância. Formemos por isso uma infância sadia física e moralmente e teremos um povo físico e moralmente sadio. (DIÁRIO Popular, $27 / 08 / 1945$, p. 21$)$.

Havia na sociedade pelotense uma preocupação com o futuro das crianças pobres no sentido de evitar possíveis infrações, dadas as precárias condições em que viviam. A educação assistencialista / compensatória teve na Casa da Criança São Francisco de Paula a marca do pioneirismo na cidade, quanto à concretização de ações filantrópicas voltadas para a primeira infância, sem o caráter asilar.

Como um "estabelecimento destinado à educação da infância e juventude feminina", o Colégio São José17 (CSJ) implantou o curso de "Primeiras Lettras" e o "Curso Elementar"18 ( $1^{\circ}$ ao $4^{\circ}$ ano), matriculando crianças a partir de cinco anos de idade. Em 1916, foram registradas três crianças com quatro anos, sem especificar para qual turma/curso, mas de acordo com anúncio de um jornal local, o funcionamento do Jardim de Infância iniciou em março daquele ano: "Annexo ao collegio funcionará o Jardim da Infância para creanças de ambos

17 Fundado em 1910 pelas Irmãs da Congregação de São José, iniciou suas atividades sob a direção de Madre Saint Maurice. Essas Irmãs da Igreja Católica vieram da França a convite do Intendente Municipal Dr. José Barboza Gonçalves, com o apoio do Bispo de Porto Alegre Dom Cláudio Gonçalves Ponce de Leon. O Intendente empenhou-se nessa tarefa para atender ao pedido de sua filha, Maria, que não queria sair da cidade de Pelotas para estudar (informação contida no histórico dessa instituição; primeira aluna matriculada: Maria Barboza Gonçalves).

18 Fonte: primeiro Livro de Registro de Matrículas do CSJ. 
os sexos, desde 4 annos até 7." (DIÁRIO Popular, 21/10/1916, p. 3). No ano seguinte, o mesmo jornal noticiava outra propaganda da instituição: "Funciona annexo o 'Jardim da Infância', para ambos os sexos e montado sob todas as regras da moderna pedagogia.” (DIÁRIO Popular, 21/01/1917, p. 1). Ainda em 1916, com a inauguração de prédio próprio, passou a oferecer internato para meninas e moças, além do externato, reiterando assim o feminino como o seu público-alvo, cuja educação alicerçava-se em princípios religiosos católicos.

Mesmo priorizando a educação feminina, o Colégio São José matriculou alguns meninos desde o início das atividades do Jardim de Infância. Conforme o Art. $5^{\circ}$, do Regimento Interno de 1965, "Os cursos funcionarão com alunos do sexo feminino, excetuando-se o pré-primário que é misto.” E acrescenta, no parágrafo único, "enquanto houver conveniência para o Colégio, manter-se-ão alunos do sexo masculino, nas primeiras séries do curso primário". (REGIMENTO Interno CSJ, 1965). Possivelmente, a conveniência mencionada refere-se ao comportamento dos meninos em relação às meninas e moças do educandário no que diz respeito ao corpo e à sexualidade e suas manifestações. O cumprimento dessa determinação se verificou durante várias décadas, pois são vários os registros de matrículas de meninos em turmas do Ensino Pré-Primário (Jardim de Infância) e Ensino Primário que compunham o Curso de Aplicação do Curso Normal dessa instituição; "servindo, pois, de campo de prática, observação e experimentação para as normalistas, sob a orientação do Serviço de Orientação Didática”. (REGIMENTO Interno CSJ, 1965). Nesse estabelecimento de ensino, o "Curso Pré-Primário visa desenvolver as potencialidades da criança e prepará-la para realizar satisfatòriamente a aprendizagem. Proporcionará situações tais que favoreçam o desenvolvimento da criança em tôdas as áreas de sua personalidade.” (REGIMENTO Interno CSJ, 1965, art. $7^{\circ}$ ).

Jeanne Évrard-Fiquemont (1958, p. 24) destaca que no Jardim de Infância a criança era "objeto constante de observação e da solicitude da educadora que está sempre pronta para guiar, ajudar, aconselhar, preservar, conter ou ajudar." Para essa educadora francesa, além de aprender bons hábitos de higiene e boas maneiras, no jardim, a criança "aprende a pensar bem, observar e julgar, mostrar-se paciente, justa, honesta, boa, prestativa”. (ÉVRARD-FIQUEMONT, 1958, p. 25). Ou seja, nesses espaços havia um investimento na formação de "uma criança cordata, cumpridora dos seus deveres, educada para a obediência". (FELIPE, 2000, p. 84). Entretanto, essa disciplina não era apenas aludida às crianças, mas também as professoras eram alvos desse controle, considerando a importância de seu trabalho na formação de cidadãs e cidadãos brasileiros em cujas mãos estaria o futuro da nação. Como exemplo disso, tem-se os inúmeros textos que referem essa responsabilidade e essa expectativa em torno desses 
sujeitos, como o transcrito abaixo sobre a Primeira Jornada da Educação Pré-primária ${ }^{19}$, realizada em Pelotas.

\section{A DELEGACIA DA $5^{\text {a }}$ DR DA SEC}

A professora Laura Machado Iruzum Delegada da 5 a DR da SEC, falou: 'A Primeira Jornada Regional de Educação Pré-Primária, que será realizada nesta cidade de 18 a 20 do corrente, representa uma oportunidade para as professôras Jardineiras que trabalham nos Grupos Escolares Estaduais, Municipais e Escolas Particulares, atualizarem seus conhecimentos relativos ao trabalho que realizam na formação de hábitos nas crianças, que frequentam os Jardins de Infância. Será de grande utilidade a frequência a esta Jornada, pois nela serão debatidos assuntos de relevante interêsse para o trabalho das professôras que têm a seu cargo a responsabilidade de moldar o caráter, ensinar boas maneiras aperfeiçoar as inclinações positivas de cada pequeno ser confiado à sua capacidade e dedicação. (DIÁRIO Popular, 19/04/1969, p. 4, $2^{\circ}$ caderno).

Se, por um lado, a ideia da educadora nata (ARCE, 2001) estava muito presente nos discursos daquela época; por outro, a organização das professoras da Educação Infantil através de encontros específicos como o citado acima promoveu a discussão de problemas comuns do cotidiano dessas profissionais e as possíveis soluções, pautadas por estudos e teorias valorizadas naquele período sobre a educação da infância.

\section{MAGISTÉRIO DISCUTE AQUI A EDUCAÇÃO PRÉ-PRIMÁRIA [...] A Diretora do Departamento de Ensino Primário Municipal, professora Ana Maria de Oliveira Costa assim se pronunciou: [...] 'A oportunidade rara, virá certamente enriquecer o alto nível educativo de nosso magisté- rio, que tem na dinâmica educação pré-primária, valioso alicerce para a estrutura pessoal de seu educando.' [...] \\ A presidente da Associação Sul-Riograndense de Professores, professora Olga Maria Dias Bainy entidade patrocinadora da Jornada disse: 'A I}

19 "Este evento aconteceu no período de 18 a 20/04/1969 e foi promovido pela Associação Sul-Riograndense de Educação Pré-Primária, com a colaboração da Associação Sul-Riograndense de Professores e do Departamento do Ensino Primário da 5a Delegacia Regional da Secretaria de Educação e Cultura/RS. Os temas abordados foram os seguintes: 'Importância da Educação Pré-Primária'; 'Atividades no Jardim de Infância'; 'Condições para funcionamento de um Jardim de Infância'; 'Atuação da Jardineira'; ‘Artes, Música e Recreação’.” (DIÁRIO Popular, 15/04/1969, p. $5,1^{\circ}$ caderno). 
Jornada Regional de Educação Pré-Primária tem por finalidade básica, despertar o mestre em sua significativa responsabilidade, frente ao educando. Nossa intenção precípua é atingir a criança em formação, a fim de propiciar-lhes condições de um desenvolvimento sadio e perfeito, como único meio capaz de lhe permitir sua realização. Assim sendo nada melhor do que buscar chegar até ela, através daquele que com ela convive, favorecendo-o com o conhecimento de novas técnicas educativas. O pré-escolar carece de uma atenção especial, face às necessidades inerentes à faixa de idade que atravessa e para isso urge que seus educadores tenham igualmente um preparo especializado. [...]. (DIÁRIO Popular, 19/04/1969, p. $4,2^{\circ}$ caderno).

As palavras proferidas pela presidente da Associação Sul-Rio-grandense de Professores (ASRP) mostram o objetivo principal do evento que é "atingir a criança em formação", para que ela tenha "um desenvolvimento sadio e perfeito, como único meio capaz de lhe permitir sua realização". Dessa forma, a professora se apresenta como aquela que se incumbe da tarefa de "formar" a criança, mas precisa primeiro se (in)formar para tal desafio, pois é tida nesse contexto como uma ponte para se chegar à criança, alvo do trabalho sugerido. Tem-se aqui uma espécie de governo (na perspectiva de Foucault) da criança, através do governo "daquele [/a] que com ela convive".

Para Jorge Ramos do Ó (2009, p. 100), "Governar é, assim, um exercício permanente que entrecruza os comportamentos de todos e cada um de modo homólogo". Dessa maneira, esse autor salienta que, ao longo da história, o poder deixa de se situar na lógica da dominação para conectar-se à liberdade e autonomia, cada vez mais presentes nos modos de produção de cidadãos e cidadãs.

Segundo Silva (1995, p. 191-2), as modernas formas de governo da conduta humana dependem de formas de saber que, por sua vez, definem e determinam as condutas a serem governadas, indicando o que deve ser pensado sobre elas e quais os meios para melhor governá-las. A partir disso, ressalta a existência do controle externo da conduta combinado com o autocontrole - que Foucault designou de "tecnologias da dominação" e "tecnologias do eu", respectivamente - tendo em vista a produção do sujeito autogovernável. E acrescenta que a produção desse sujeito é o objetivo da ação de várias instituições como, por exemplo, a educação; enfatizando que para governar é preciso conhecer os indivíduos a serem governados e, nessa lógica, para autogovernar-se é necessário conhecer-se a si próprio. Nesse jogo, portanto, se estabelecem relações de poder-saber e determinadas verdades são produzidas a respeito dos indivíduos nelas envolvidos. Como afirma Foucault (1985, p. 21), "Não há relação de poder sem constituição de um campo de saber, como também, reciprocamente, todo 
saber constitui novas relações de poder. Todo ponto de exercício do poder é, ao mesmo tempo, um lugar de formação de saber".

Há uma interdependência entre poder e saber. O poder utiliza o saber e vice-versa. Nesse universo, as identidades são forjadas. No que concerne à escola, as marcações identitárias têm sido aceitas e reforçadas, muitas vezes, sem indagações. Sendo, portanto, aceitas como "naturais". Como, na perspectiva de gênero, as diferenças entre homens e mulheres são construções simbólicas, uma invenção social, política e cultural, é através da representação que as mulheres, em sua maioria, assumem a educação das crianças tanto na família como na escola, movidas pelos discursos que circulam na sociedade, demarcando espaços e funções sociais.

Assim, as professoras da Educação Infantil foram colocadas como importantes agentes na produção do sujeito cidadão brasileiro almejado para a época investigada, adquirindo a educação pré-escolar um papel relevante nesse processo de preparar as crianças pequenas para a Escola Fundamental. Então, era indispensável possibilitar o acesso da criança à escola mais cedo, a fim de prepará-la para os anos subsequentes de escolarização. Porém, essa antecipação não deveria significar um enfado para a criança. Ao contrário, deveria ser um tempo de descobertas e de realização de atividades interessantes e lúdicas, conduzido por professoras preparadas para esse fim.

A exigência de preparação das professoras para atuar junto às crianças pequenas, no Jardim de Infância, enfatiza a oposição à ideia de que bastaria amá-las e cuidá-las através do sentimento maternal. Tornava-se necessária uma preparação adequada para atuar naquela área da educação formal, pois um suposto "dom natural" da mulher não era suficiente para educar os/as pequeninos/as. Então, caía por terra a justificativa embasada apenas na natureza feminina - aquela que defende as "funções femininas" na sociedade, a partir de explicações biológicas. A demanda exigia profissionais capazes de atender ao objetivo crescente da Educação Infantil, isto é, preparação para o Ensino Fundamental que enfrentava alto índice de reprovação e evasão. Cada vez mais seria necessário investir na formação docente, o que justificaria a organização de eventos como a I Jornada da Educação Pré-Primária, mencionada anteriormente.

A referida Jornada foi ministrada por membros da Associação Sul-Rio-grandense de Educação Pré-Primária ${ }^{20}$ (ASREP), com sede em Porto Alegre/ RS. Segundo a presidente da ASREP, professora Istelita Cunha:

20 Fundada em 14 de maio de 1965; filiada à Organização Mundial de Educação Pré-Primária (OMEP). 
Trabalhamos principalmente nesta faixa de cursos, procurando sempre esclarecer tanto o professor formado, como aquelas pessoas que tem responsabilidade sôbre o pré-escolar, mas que não são formados, e acho que aí está a grande missão da ASREP. [...] Membros da Diretoria da Casa da Criança São Francisco de Paula que nos procuraram, para se associarem, nos levaram a vir de imediato a Pelotas, exatamente porque sentimos entusiasmo, a vontade que as professôras desta cidade demonstraram em receber alguma coisa de caráter didático, relacionado com o pré-primário. (DIÁRIO Popular, 23/04/1969, p. 4, $2^{\circ}$ caderno).

Nota-se, por meio desse relato, que havia preocupação e comprometimento por parte das professoras com sua formação, demonstrando a importância que o profissionalismo nessa área estava adquirindo, o que contribuiu com a consolidação dos Jardins de Infância na cidade de Pelotas, bem como sua expansão. Havia, portanto, um movimento no Estado do Rio Grande do Sul e em outros lugares do Brasil que buscava o fortalecimento do trabalho com/na Educação Infantil, a partir de estudos e investimentos na formação de professores/as. Outro fator que proporcionou a expansão dos Jardins de Infância refere-se ao fato da elite da sociedade pelotense procurar esse espaço como sinônimo de modernidade; porque muitas das mulheres dessa camada social não trabalhavam fora de casa, mas enviavam seus/suas filhos/as para esses espaços educativos.

Nesse sentido, a Educação Infantil no Colégio São José já havia recebido novos investimentos a partir do início da década de 1960, conforme anúncio feito pela diretora nos jornais locais: "sofrerá radical, transformação o Jardim da Infância do Colégio São José, devendo nêle serem introduzidas inovações que, por seu avanço pedagógico, deverão beneficiar centenas de crianças." A reportagem também explicita que "para concretizar o empreendimento, a direção daquele tradicional educandário da 'Princesa do Sul' 21 termina de contratar a Irmã Benjamina, mestra especializada no Rio de Janeiro e que, sem dúvida, pelas credenciais que possue, deverá realizar trabalho dos mais proveitosos nêsse terreno educacional.” (DIÁRIO Popular, 21/01/1960, p. 3; A OPINIÃO Pública, 22/01/1960, p. 6). Essa informação reitera a consolidação desse espaço educativo infantil, através da especialização exigida dessas profissionais para nele atuarem, evidenciando a qualidade almejada e o necessário investimento para tal.

Salientava-se também o ambiente da sala de aula que deveria ser rico em materiais para proporcionar aprendizagens significativas às crianças pequenas:

21 Como é conhecida a cidade de Pelotas. Cognome de origem controvertida. Para maiores informações, consultar Magalhães (1993, 2003). 
[...] o Jardim, atualmente, está funcionando dentro dos modêlos e técnicas modernas. Suas atividades são planejadas de modo a atender aos interêsses da criança e ao seu nível social.

O próprio ambiente da sala é tão atraente e rico em material que as crianças se sentem motivadas para a ação. (REVISTA Cinqüentenário do Colégio São José, 1910-1960, p. 109).

Quanto ao Instituto Estadual de Educação Assis Brasil (IEEAB), o Jardim de Infância ${ }^{22}$ tinha como referência o trabalho desenvolvido em escolas de Porto Alegre, que foram visitadas por professoras desse educandário, antes da sua implantação. Há registros de que ao ser transferido para o prédio atual, o Jardim de Infância era composto por duas turmas: a verde e a rosa, conforme as cores das paredes das respectivas salas e organizadas por faixa etária, sendo a primeira destinada às crianças de quatro a cinco anos e a segunda turma para crianças de cinco a seis anos. As turmas eram mistas e não havia a preocupação em separar por gênero conforme as cores, como muitas vezes é reforçado em algumas culturas. Isso tem sido justificado pela representação de que crianças pequenas são assexuadas e, portanto, não oferecem o menor perigo. (FELIPE, 2000). Sendo, então, admitida a educação mista até os primeiros anos do Ensino Fundamental, mesmo em instituições que priorizavam a educação feminina, especialmente aquelas que mantinham o Curso Normal. Essas turmas de crianças faziam parte do Curso de Aplicação, servindo como campo para as diversas práticas de ensino realizadas pelas normalistas.

De acordo com os registros escolares do IEEAB, as professoras/“jardineiras" eram/deveriam ser zelosas, carinhosas, exemplos para as crianças, mas também atualizadas em sua área de atuação, de acordo com os fragmentos de atas elaboradas em reuniões pedagógicas, destacados a seguir.

Primeiramente falou a Prof ${ }^{a}$ Leopoldina Porto, sôbre os seguintes assuntos: 1) Histórico do Jardim de Infância, explicando a origem do nome Jardim de Infância, em que as crianças são comparadas às flôres e a professôra é a Jardineira que com zêlo e carinho cuida das mesmas [...]. (LIVRO de Atas do Jardim de Infância da Escola Normal 'Assis Brasil' de Pelotas, Ata $\left.n^{\circ} 18,24 / 03 / 1961\right)$.

[...] Antes de encerrar a sessão a professôra assistente solicitou às jardineiras a observância da pontualidade, no que deverão dar exemplo às

22 Foi inaugurado em 04 de setembro de 1940, no prédio localizado na Rua General Osório esquina com a Rua Dr. Cassiano. Atualmente, o IEEAB localiza-se na Rua Antônio dos Anjos, nº 296. 
crianças. (LIVRO de Atas do Jardim de Infância da Escola Normal 'Assis Brasil' de Pelotas, Ata n $\left.{ }^{\circ} 58,22 / 08 / 1964\right)$.

[...] j) - Notificação do ofício circular de n ${ }^{\circ} 46$ da Secretaria de Educação e Cultura de nosso Estado, assunto: realização na capital (Porto Alegre) de onze (11) a quinze (15) de outubro da ' $1{ }^{a}$ Conferência Estadual de Educação Pré-primária’. [...]. (LIVRO de Atas do Jardim de Infância da Escola Normal 'Assis Brasil' de Pelotas, Ata nº 61, 19/09/1964).

As atas dessas reuniões informam sucintamente os assuntos que haviam sido tratados. Nesses momentos era possibilitado o compartilhamento de experiências vivenciadas em cursos pelas professoras, tornando-as multiplicadoras, diante das dificuldades que teriam de todas participarem dos mesmos eventos. Então, conforme excerto de uma ata - transcrito abaixo -, o trabalho com a Literatura Infantil era uma sugestão importante, ao se propor atividades que poderiam/deveriam ser desenvolvidas com as crianças. Convém lembrar que a literatura tinha uma função especial naquela época, ao enfatizar as lições de moral contidas nas histórias infantis, caracterizando uma forte preocupação com a formação moral das crianças. Além disso, a Psicologia também foi citada, apontando a possível influência das teorias psicológicas no desenvolvimento do trabalho docente com crianças pequenas, fato que se acentuou a partir da metade do século passado aqui no Brasil.

[...] Na referida reunião, a colega Clélia Guedes, fez o comentário do curso para jardineiras que assistiu em Porto Alegre. Falou sôbre Psicologia, Literatura infantil e mostrou exemplos de trabalhos para serem feitos pelas crianças. [...]. (LIVRO de Atas do Jardim de Infância da Escola Normal 'Assis Brasil' de Pelotas, Ata n 24, 27/10/1961).

Segundo Felipe (2000, p. 66), a Psicologia "pode ser caracterizada como uma disciplina científica estreitamente relacionada a determinadas práticas de regulação social", integrando-se às práticas diárias de governo dos sujeitos, por meio das estratégias de confissão. Para tanto, se tornou imprescindível o conhecimento de si e o autogoverno. Esse pressuposto foi incorporado pelo trabalho nos Jardins de Infância, através do exercício de poder-saber, uma vez que se pretendia substituir os antigos castigos pelo diálogo, tão necessário para o estabelecimento de normas de conduta que deveriam ser construídas pela 
professora, juntamente com as crianças. Dessa forma, a escolarização teve como uma de suas metas "observar a criança, conhecê-la para melhor controlá-la e categorizá-la (normal/anormal)". (FELIPE, 2000, p. 67).

No que concerne ao trabalho desenvolvido pelas professoras nos Jardins de Infância, havia um acompanhamento por parte dessa instituição através da Professora Assistente do Pré-Primário e, em determinados momentos, por uma orientadora da Secretaria de Educação/RS, como afirma o trecho de uma ata de reunião pedagógica:

[...] foram tratados os seguintes assuntos: a) visita da orientadora do Centro de Pesquisas e Orientação Educacional de Pôrto Alegre [...] que virá observar se os objetivos de nosso Jardim estão sendo desenvolvidos de maneira certa. (LIVRO de Atas do Jardim de Infância da Escola Normal 'Assis Brasil' de Pelotas, ATA n ${ }^{\circ}$ 119, 22/10/1966).

Isso demonstra mais uma vez a preocupação que havia com a profissionalização e a formação continuada das professoras do Jardim, pois se tratava de uma área nova e que para a sua consolidação necessitava de um acompanhamento pedagógico voltado para as características específicas da faixa etária das crianças atendidas. Por outro lado, esse acompanhamento também possuía um caráter controlador do trabalho docente; em outras palavras, o governo das professoras da educação pré-primária, pois existia um projeto de educação para a primeira infância em fase de implementação cujo objetivo maior era o sucesso das crianças na escola primária. Naquele período, acentuou-se a chamada educação compensatória/preparatória, cujo investimento residia na preparação das crianças para o Ensino Fundamental, principalmente as pertencentes às camadas pobres da população.

Com esse enfoque, a Escola Municipal de Ensino Fundamental Luciana de Araújo implanta a primeira turma de Jardim de Infância, na rede municipal de ensino, em 24 de junho de 1953, cuja justificativa e objetivo principal são especificados da seguinte maneira:

Orientar uma criança para uma vida feliz e útil, não é fácil. Os pais podem contribuir muito e quase totalmente para auxiliar o filho a agir da melhor maneira possível. Embora assim sendo, tornava-se cada vez mais claro que essa orientação, por diversos fatores, não é a propícia às crianças que ingressaram nos primeiros anos, das escolas municipais. Inúmeros casos 
dessa ordem levaram a Orientadora de Ensino, neste setor, Maritana Pires Baptista, a preocupar-se seriamente com o problema e idealizar um meio, um planejamento, afim de que um grupo de professôras colaborassem na tarefa dos pais e encontrasse para as crianças um meio de satisfação, nas atividades escolares e em conseqüência bom êxito na futura alfabetização. A feliz idéia foi tomando vulto e depois de vencidos uma série de obstáculos surgiu real, luminosa, amadurecida na forma de uma bela salinha contendo tudo que se possa realizar no reino encantado da imaginação infantil. Estava fundado o $1^{\circ}$ Jardim de Infância das Escolas Municipais, cujo principal objetivo era tornar crianças, entre 5 e 6 anos, felizes e fácilmente adaptáveis ao meio escolar. (HISTÓRICO do Jardim de Infância, manuscrito).

A partir desse fragmento do texto investigado, é possível constatar a preocupação com o futuro desempenho das crianças no Ensino Fundamental, especialmente no que diz respeito à "futura alfabetização".

Outro espaço escolar importante na educação das crianças pequenas na cidade de Pelotas, em meados do século XX, foi a Escola Municipal de Arte e Infância Ruth Blank, que recebeu esta designação em homenagem à sua idealizadora e fundadora, a professora que também foi a primeira diretora dessa instituição. A elaboração e a concretização desse projeto tiveram na professora Ruth a "Educação através da Arte" como ideal, conforme o documento "Plano de Criação de uma 'Escolinha de Arte' no município de Pelotas" (1963), contando com o apoio e o investimento por parte do governo municipal. Algumas informações importantes sobre o projeto de sua implantação estão nos excertos abaixo, especialmente no que se refere ao estudo e preparação de professoras para assumirem o trabalho proposto, contrariando o que muito se difunde que o principal no magistério seria o "gosto pelo que se faz" e o "jeitinho com as crianças". Todo o trabalho exige formação adequada e competência profissional.

Em outubro de 1962 a professora Ruth E. Blank, solicitada pela sra. Diretora de Educação, frequentou, em PÔRTO ALEGRE no período de 8 de outubro à 8 de novembro o Curso Intensivo de ARTE na EDUCAÇÃO, realizado na ESCOLINHA DE ARTE da Divisão de Cultura, da Secretaria de Educação e Cultura do R. G. Sul. Ministraram o referido curso grandes e abalisados educadores nacionais e estrangeiros. Por determinação da Sra. Diretora de Educação, a professôra Ruth E. Blank, organiza o Plano de Criação de uma ESCOLINHA DE ARTE em Pelotas, junto da Diretoria da Educação Municipal. (RELATÓRIO contendo o Histórico da Escolinha Municipal de Arte, 1962). 
Curso de preparação, para professôres municipais, ministrado na Diretoria da Educação Municipal. Objetivo do referido curso: Preparação do material humano para funcionamento da 'ESCOLINHA MUNICIPAL DE ARTE'. [...] Foi criada uma Escolinha Municipal de Arte, funcionando em prédio próprio, na Praça Júlio de Castilhos [...]. O objetivo principal desta Escolinha é tornar a criança mais feliz e o adulto mais sensível á ARTE. Finalidade principal: Educar a criança e reeducar o adulto pela ARTE. (DOCUMENTO arquivado na Escolinha Municipal de Arte contendo as "Observações do Relatório da Diretoria de Educação", 1963).

Portanto, a implantação desse projeto em Pelotas teve sua trajetória marcada pela busca do profissionalismo no desenvolvimento do trabalho docente, desde a realização de curso específico por parte da professora Ruth Blank, responsável pela sua implementação, até o curso de preparação do material humano que foi destinado ao funcionamento da Escolinha Municipal de Arte, tendo em vista a consecução do seu objetivo principal, acima mencionado. É importante ressaltar que a criação de escolinhas de Arte no Brasil se deve ao educador Augusto Rodrigues que fundou a Escolinha de Arte do Brasil (1948), no Rio de Janeiro instituição que serviu de orientação para os trabalhos desenvolvidos em Pelotas.

Uma característica interessante dessa escola é a sua localização junto ao Parque Dom Antônio Zattera, antiga Praça Júlio de Castilhos, rodeada por uma singular área verde no Centro de Pelotas. Além disso, merece destaque o público-alvo dessa instituição que, em seus primórdios, era bastante diversificado, pois atendia em turmas distintas - nos turnos manhã, tarde e noite - desde crianças pequenas até adultos. Havia, também, o atendimento de pessoas com deficiência intelectual, demonstrando que a inclusão escolar fazia parte desse projeto em sua origem.

A partir dessas considerações, é possível afirmar que essas instituições alicerçaram-se em concepções filosóficas e pedagógicas diversas, dentro de determinadas estruturas econômicas e políticas mantidas pela sociedade local, em consonância com o contexto brasileiro daquela época. Portanto, seguiam as tendências educacionais, historicamente situadas e legitimadas pelas práticas sociais.

\section{Considerações finais}

A partir da investigação realizada em instituições pioneiras no atendimento da primeira infância, em Pelotas, é possível afirmar a preocupação com 
a proteção e educação das crianças pequenas e com a formação de professores/ as para essa área. Cabe destacar que nesses estabelecimentos educacionais, em determinados períodos, ficaram registradas as buscas por um atendimento especializado e de acordo com as orientações consideradas modernas em centros mais desenvolvidos, especialmente nas capitais - Rio de Janeiro (Então capital do Brasil) e Porto Alegre (capital do Rio Grande do Sul). Isso sinaliza o caráter inovador e avançado atribuído aos espaços infantis que estavam sendo implantados ou remodelados, a fim de atender uma parcela da população pelotense atenta às tendências mundiais e nacionais no que concerne ao atendimento de crianças pequenas.

Portanto, houve um crescente investimento na formação das professoras do Jardim de Infância, em Pelotas, a partir da década de 1960, conferindo à cidade certo destaque nessa área da educação em termos de região sul do Estado/RS, sendo os cursos de especialização - promovidos pelo IEEAB - procurados, também, por profissionais de outros municípios.

Além disso, com a Lei de Diretrizes e Bases da Educação Nacional (Lei n ${ }^{\circ}$ 4.024/61), a educação pré-primária - ministrada em escolas maternais ou Jardins de Infância - foi incluída no sistema de ensino e empresas que tivessem mães de menores de sete anos foram estimuladas a organizar e manter essas instituições, por iniciativa própria ou em cooperação com os poderes públicos. Essas foram algumas condições que favoreceram a expansão dos espaços infantis em vários municípios brasileiros, inclusive em Pelotas.

Considerando os materiais coletados e os contextos nos quais eles foram produzidos, tornou-se possível apresentar alguns elementos que compunham o cenário no qual as professoras desenvolveram seu trabalho com crianças pequenas na cidade de Pelotas, mas que não se restringiram ao âmbito local por serem parte de um contexto sócio-histórico mais amplo.

Através dos excertos destacados neste artigo é possível visibilizar como as professoras foram representadas, cujo exercício da docência serviu como uma possibilidade de resolução dos problemas sociais, dentre eles a prevenção da criminalidade. As exigências atribuídas às docentes incorporam os valores pertinentes a um dado período histórico, com seus diferentes momentos e necessidades apontadas. Fica evidente a busca do profissionalismo em detrimento do "amadorismo", tantas vezes sugerido por diferentes enunciados que referem a educação da infância em nosso país. Isso, pelo menos no papel, é reafirmado e se efetivou nos Jardins de Infância das instituições investigadas, conforme os documentos escolares arquivados.

A partir do exposto, é possível afirmar que a formação docente para a Educação Infantil não é algo recente. Essa preocupação já existia em Pelotas, na década de 1940, ao serem registrados os estudos e observações in loco em 
escolas da Capital Porto Alegre que mantinham turmas de Jardim de Infância, por professoras formadas no Curso Normal, antes da implantação dessa proposta no Instituto Estadual de Educação Assis Brasil. Nessa instituição foi ministrado, na década de 1960, o Curso de Especialização - "Formação de Professores Especializados em Educação Pré-Primária" - previsto na legislação em vigor, sendo uma escola de referência na região sul do Estado do Rio Grande do Sul. Os documentos escolares pesquisados nas escolas indicam que somente professoras formadas no Curso Normal e, preferencialmente, as que tivessem esse Curso de Especialização poderiam atuar em turmas de Jardim de Infância em Pelotas.

Entretanto, o cumprimento da formação no Curso Normal e a especialização em educação pré-primária, como exigência para atuar no Jardim, nem sempre se manteve nas décadas posteriores diante do aumento da demanda e de interesses políticos, dentre outros fatores que podem ser destacados. Porém, deixa claro que a exigência de formação específica não surge apenas com a Lei de Diretrizes e Bases da Educação Nacional (LDB), Lei no 9.394/1996, mas já era uma preocupação em meados do século XX. O que essa Lei prevê é a exigência de formação para aqueles/as que trabalham na Educação Infantil (atendimento de crianças de zero a cinco anos de idade - creche e pré-escola) e não apenas dos/as que atuam na pré-escola (atendimento de crianças de quatro a cinco anos). Mesmo assim, o seu cumprimento não atingiu o nível esperado no século XXI; ainda necessita de muitos investimentos em formação inicial de professores/as para se efetivar em sua totalidade.

\section{Documentos consultados}

A OPINIÃO Pública, 09/06/1943; 22/01/1960, Pelotas.

ATA n $^{\circ} 137,30 / 05 / 1952$, Colégio São José, Pelotas.

DIÁRIO Popular, 21/10/1916; 21/01/1917; 27/08/1945; 21/01/1960; 07/07/1968; 15/04/1969; 19/04/1969; 23/04/1969, Pelotas.

DOCUMENTO arquivado na Escolinha Municipal de Arte contendo as "Observações do Relatório da Diretoria de Educação", Pelotas, 1963.

HISTÓRICO do Jardim de Infância, manuscrito, Escola Municipal de Ensino Fundamental Luciana de Araújo, Pelotas.

LIVRO de Atas do Jardim de Infância da Escola Normal 'Assis Brasil', Ata ${ }^{\circ} 18$, 24/03/1961; Ata no 24, 27/10/1961; Ata no 58, 22/08/1964; Ata no 61, 19/09/1964, Ata $\mathrm{n}^{\mathrm{o}} 119,22 / 10 / 1966$, Pelotas. 
LIVRO de Atas $n^{\circ}$ 1, da Creche São Francisco de Paula, Ata n 71, 25/08/1944, Pelotas. REGIMENTO Interno do Colégio São José, Pelotas, 1965.

RELATÓRIO contendo o Histórico da Escolinha Municipal de Arte, Pelotas, 1962.

RELATÓRIO da Presidente: Ano social de 1939 a 1940, 26/05/1940, Casa da Criança São Francisco de Paula, Pelotas.

REVISTA Cinqüentenário do Colégio São José, 1910-1960, Pelotas, 1960.

\section{REFERÊNCIAS}

ARCE, Alessandra. Documentação Oficial e o Mito da Educadora Nata na Educação Infantil. Cadernos de Pesquisa, São Paulo: Fundação Carlos Chagas, n. 113, p. 167184, jul. 2001.

ARCE, Alessandra. A Pedagogia na 'Era das Revoluções' - uma análise do pensamento de Pestalozzi e Froebel. Campinas: Autores Associados, 2002a.

ARCE, Alessandra. Friedrich Froebel: o pedagogo dos jardins-de-infância. Petrópolis: Vozes, $2002 b$.

DO Ó, Jorge Ramos. A governamentalidade e a História da Escola Moderna: outras conexões investigativas. Educação \& Realidade, Porto Alegre: UFRGS/FACED, v. 34, n. 2, p. 97-117, maio/ago. 2009.

ÉVRARD-FIQUEMONT, Jeanne. Jardim de Infância. São Paulo: Flamboyant, 1958.

FELIPE, Jane. Governando mulheres e crianças: Jardins de Infância em Porto Alegre na primeira metade do século XX. 201 f. Tese (Doutorado em Educação) - Universidade Federal do Rio Grande do Sul, Porto Alegre, 2000.

FOUCAULT, Michel. História da Sexualidade 2: o uso dos prazeres. Rio de Janeiro: Graal, 1984.

FOUCAULT, Michel. Microfísica do Poder. Rio de Janeiro: Edições Graal, 1985.

KISHIMOTO, Tizuco Morchida. Os Jardins de infância: as escolas maternais de São Paulo no início da República. Cadernos de Pesquisa, São Paulo: Fundação Carlos Chagas, n. 64, p. 57-60, 1986.

KUHLMANN JR, Moysés. Infância e Educação Infantil: uma abordagem histórica. 2. ed. Porto Alegre: Mediação, 2001.

LARROSA, Jorge. Tecnologias do eu e educação. In: SILVA, Tomaz Tadeu da (Org.). $O$ Sujeito da Educação: Estudos foucaultianos. 4. ed. Petrópolis, RJ: Vozes, 2000. p. 35-86. 
LONER, Beatriz Ana. A Formação da Classe Operária. Tese (Doutorado em História) - Universidade Federal do Rio Grande do Sul, Porto Alegre, 1998. 2 v.

LOURO, Guacira Lopes. Gênero, sexualidade e educação: uma perspectiva pós-estruturalista. 3. ed. Petrópolis, RJ: Vozes, 1999.

MAgAlHÃES, Mario Osório. Opulência e cultura na Província de São Pedro: um estudo sobre a história de Pelotas (1860-1890). Pelotas: Editora da UFPel/Livraria Mundial, 1993.

MAGALHÃES, Mario Osório. História aos domingos. Pelotas: Editora Livraria Mundial, 2003.

OLIVEIRA, Zilma Ramos de. A criança e seu desenvolvimento: perspectivas para se discutir a Educação Infantil. São Paulo: Cortez, 1995.

OLIVEIRA, Zilma Ramos de. Educação Infantil: fundamentos e métodos. São Paulo: Cortez, 2002.

PINAZZA, Mônica Appezzato. Os pensamentos de Pestalozzi e Froebel nos primórdios da pré-escola oficial paulista. In: FARIA, Ana Lúcia Goulart; MELLO, Suely Amaral (Orgs.). Linguagens infantis: outras formas de leitura. Campinas: Autores Associados, 2005. p. 85-100.

SILVA, Tomaz Tadeu da. Currículo e identidade social: territórios contestados. In:

(Org.). Alienígenas na sala de aula: uma introdução aos Estudos Culturais em Educação. 3. ed. Petrópolis: Vozes, 1995. p. 190-207.

SILVA, Tomaz Tadeu da. O currículo como fetiche: a poética e a política do texto curricular. Belo Horizonte: Autêntica, 1999.

VENZKE, Lourdes Helena Dummer. “Já não vos assistirá plenamente o direito de errar, porque vos competirá o dever de corrigir": gênero, docência e Educação Infantil em Pelotas (décadas 1940-1960). 203 f. Tese (Doutorado em Educação) - Universidade Federal do Rio Grande do Sul, Porto Alegre, 2010.

VIEIRA, Lívia Maria Fraga. Creches no Brasil: de mal necessário a lugar de compensar carências rumo à construção de um projeto educativo. 347 f. Dissertação (Mestrado em Educação) - Universidade Federal de Minas Gerais, Belo Horizonte, 1986.

Texto recebido em 27 de novembro de 2014. Texto aprovado em 13 de março de 2015. 
